\title{
Algorithmic model development of B-spline non-linear electric signal decomposition
}

\author{
Semenova N. G. \\ Federal State Budgetary Educational Institution of Higher \\ Education «Orenburg State University» \\ Russia \\ tomsk@house.osu.ru
}

\author{
Semenova L. A. \\ Federal State Budgetary Educational Institution of Higher \\ Education «Orenburg State University» \\ Russia \\ 1_sem@mail.ru
}

\begin{abstract}
The developed mathematical and algorithmic nonlinear electric signal models are presented via $B$-spline decomposition. The advantage of application of decomposition of $B$-spline data record tracing in comparison with the classical empiric mode decomposition method has been fully justified. The results of software implementation of the given algorithm for $B$ spline non-linear electric signal decomposition are showed.
\end{abstract}

Keywords - non-linear electric signal; harmonics; B-spline decomposition

\section{INTRODUCTION}

At the present time, methods of spectral time analysis, used in electrical engineering, cardiology, geophysics, radiophysics, IT technologies, depending on the type of the process researched, can be divided into three groups [1]. Fourier series transformation is used for linear and stationary process research. Its main advantage is a classically elaborated theory. The disadvantage is the use of a prior defined basic set (sine and cosine functions, Walsh meander functions) and difficulty in obtaining information about time localization for amplitude and frequency signal components.

The second group of methods designed for linear and nonstationary process research is presented by wavelet analysis, Wigner-Will and Prony methods. Its main advantage is receiving information about spectral content of researched process and its time and space changes. The disadvantage is the use of a prior defined basic set (wavelets of Haar and Meyer etc.), which gives an additional error in research area.

The third group includes an empirical decomposition method (EMD), used for nonlinear and nonstationary process research. The main advantage is creation of an adaptive basic set, functionally dependent on primary data changes.

This method is based on a statement that all signals are presented by the complex of different intrinsic modes - IMF (Intrinsic Mode Functions), having amplitude and frequency modulations. As the result, researched signal $f(t)$ can be presented by a sum of mode functions $c_{i}(t)$, which quantity is defined during computation and by resulting remainder $r_{N}(t)$, which is a trend or constant: $f(t)=\sum_{i=1}^{N-1} c_{i}(t)+r_{N}(t)$.
Identification of a modal combination for registered nonlinear electric signals allows detecting higher harmonics and defining filter settings, ensuring the safe work of electric devices (asynchronous motors, transformers etc.).

The relevance of the EMD method use for data record tracing analysis involves decomposition without a priori knowledge about noise, trend and signal components. All data are extracted immediately during decomposition into empiric modes.

\section{ALGORITHM B-SPLINE DECOMPOSITION}

In this work, the authors offer an algorithm, developed on the base of the classical EMD method and, so-called, $B$-spline decomposition. It includes the following procedures (Fig. 1):

\section{Definition of extrema.}

2. Average $B$-spline definition.

3. Sifting of proto-IMF.

4. Criteria verification of $S$-number.

5. Remainder formation.

\section{Checking remainder monotoneness.}

The difference of the developed algorithm from a classical one [2] is that identification of mode functions is made not by cubic splines, but by $B$-splines. The distinctive feature of $B$ splines is formulation of smoothed diagrams allowing one to reduce errors, including mode function oscillations, and consequently to improve accuracy and effectiveness of spectral time analysis of non-linear and nonstationary processes [3, 4].

The authors will consider each of the listed procedures for the given algorithm during electric signal research $f(t)$.

\section{Definition of extrema}

The software implementation of this procedure consists of the following operational actions:

1) extremum localization in relative interval units of timeseries $h_{j}(t)$;

2) extremum elimination;

3) determining abscissa of extremums in absolute units. 


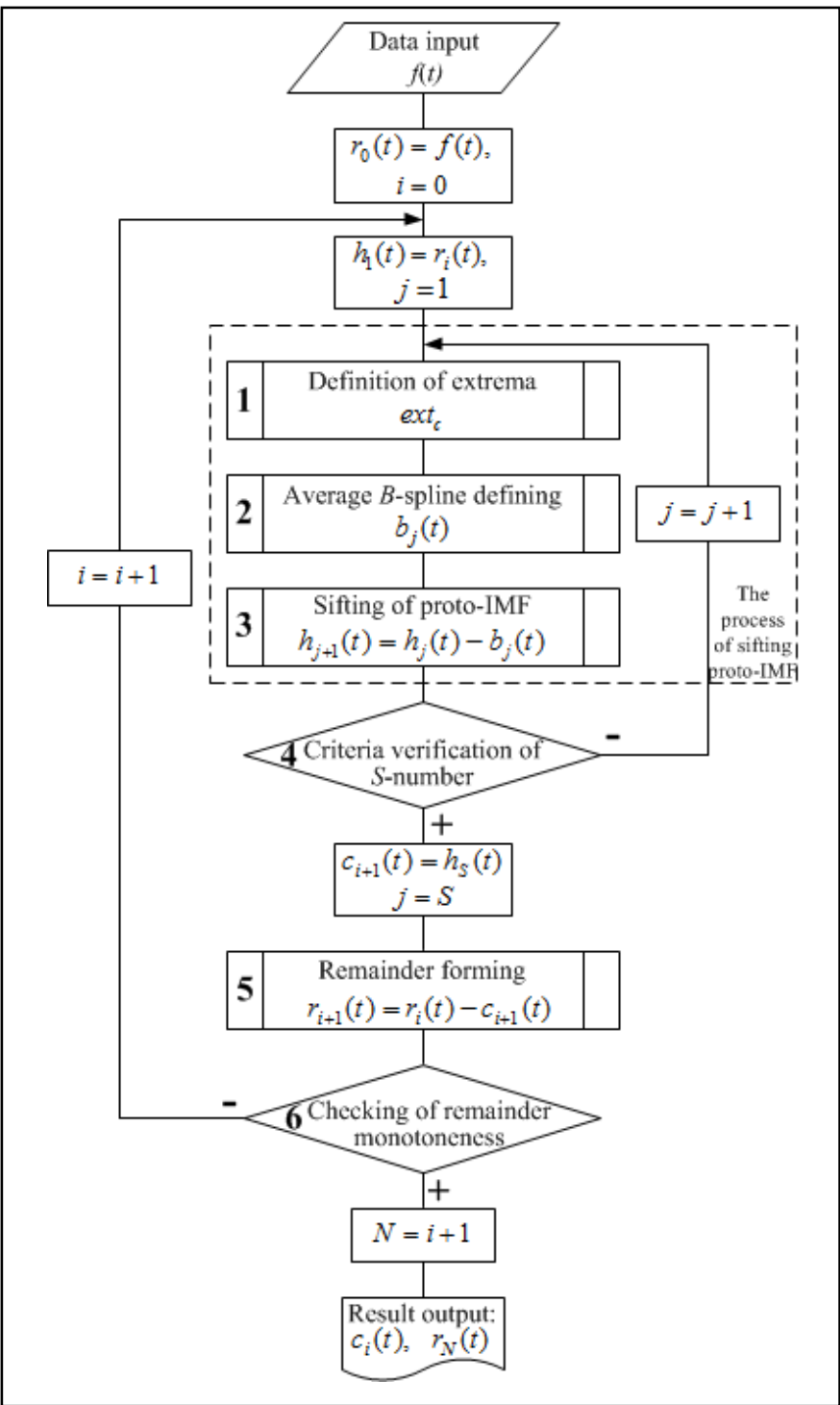

Fig. 1. Flow diagram of B-spline decomposition algorithm.

The first operation is offered to carry out with the help of the parabolas method in «flexible» interval $\mathrm{Ta}$ [5], based on step-by-step interval interchange (sliding) of $T a$ along $h_{j}(t)$ with simultaneous extremum calculation at each step of interval transfer.

The polynominal of a second degree is used as the approximating function of time-series $h_{j}(t)$ on «sliding» interval $\mathrm{Ta}$ :

$$
y\left(x_{r e l}\right)=a_{2} x_{r e l}^{2}+a_{1} x_{r e l}+a_{0},
$$

where $a_{1}, a_{2}, a_{0}$ - coefficients received from calculation data of approximating parabola [5]; $x_{\text {rel }}$ - relative units of «sliding» interval $T a$.

Determination of all extremums is made by successive interval interchange (sliding) of approximation Ta by step $\tau$ to the right till the end of time-series $h_{j}(t)$ achieved.
The localization quality of extremums depends on the length of sliding approximation interval and the step of its transfer. The use of long interval $T a$, as well as wide step $\tau$ leads to extremum omission, and the use of short one $\mathrm{Ta}$ and small one $\tau$ leads to appearance of «false» extremums. The operational action «Extremum elimination» is offered to exclude «false» extremums.

The main point of this action consists of determining rootmean-square deviation for each interval $T a$, allowing one to judge about accuracy of initial data approximation by polynomial of a second degree:

$$
\sigma=\sqrt{\frac{1}{l} \cdot \sum_{i=0}^{i-1}\left(\Delta O_{i}-O_{t g}\right)},
$$

where $l$ - the length of the «sliding» approximation interval;

$$
\begin{aligned}
& \Delta O_{i} \text { - value of an } i \text {-approximation error; } \\
& O_{\text {mean }} \text { - arithmetic mean value of an error. }
\end{aligned}
$$

Extremums, having the biggest root-mean-square deviation in «sliding» approximation interval $T a$, are eliminated.

Considering that by results of the two first procedures, the extremum abscissas are determined in relative units of «sliding» interval $\mathrm{Ta}$ (from 0 to integral part $|\mathrm{Ta} / 2|$ ). Thus, for its recalculation into absolute units, it is needed to take the third action - «Extremum abscissas determination in absolute units», which can be presented as:

$$
X_{e x t}^{a b s}=X_{\Delta+x}^{a b s}+\left(X_{e x t}^{r e l}-x\right)\left(X_{\Delta+x}^{a b s}-X_{\Delta+x-1}^{a b s}\right)
$$

where $X_{\text {ext }}^{a b s}$ - the abscissa coordinate of «sliding» interval midpoint $T a$ in absolute units;

$x$ - rounded to the first lower whole number $X_{\text {ext }}{ }^{\text {rel }}$.

Array ext $t_{c}, \mathrm{c}=0.1, \ldots, p$ of localized time-series extremums $h_{j}(t)$ is formed by results of the first $B$-spline decomposition procedure.

Graphical representation of the results of the procedure «Determination of extremums», including the considered operational actions, is shown in Fig. 2.

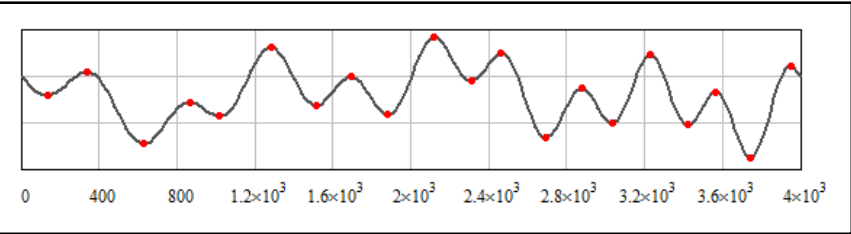

Fig. 2. Illustration of the procedure «Determining extrema».

\section{Average B-spline definition}

The software implementation of this procedure consists of the following operational actions:

1) adaptative-logistic extremum correction in the endpoints of initial signal; 
2) defining spline vertexes;

3) imaginary spline vertex forming;

4) determination of an average curve on the $B$-spline basis;

$5)$ interpolation of an average $B$-spline.

The necessity of adaptive-logistic extremum correction in the end-points of initial signal is connected to the fact that, in most cases, the function «edges» does not have extremums. It leads to ambiguity during average curve construction, which affects correctness of empirical mode extraction. The main point of adaptive-logistic correction is in analysis of nonlinear function edges [6], as a result of which limiting function points, belonging $h_{j}(t)$ to extremums, are determined.

Defining spline vertex is defining the datum of cubic spline vertex $\lambda_{k}$, which is calculated as binominal average values of localized extremums $\left(\right.$ ext $\left._{c}\right)$ :

$$
\lambda_{k}=\frac{1}{4} \cdot \sum_{n=0}^{2} \frac{2 !}{n ! \cdot(2-n) !} \cdot e x t_{c+n}
$$

To find out binominal average extremum values directly at limiting points of non-linear electric signal under study is impossible, because the first and last vertex (found via (4), will be located in triangles ext $_{0}$ ext $_{1}$ ext $_{2}$ (Fig. 3,a) and $e t_{p-2} e x t_{p-1} e t_{p}$ (Fig. 3,b), consequently. Considering that $\lambda_{k}$ is used for building an average $B$-spline, it is assumed to accept conjunction of points $\lambda_{0}$ and $\lambda_{m}$ with limiting point abscissas of time-series. In this case, vertex ordinates can be found:

- for initial vertex $\lambda_{0}$ (Fig. 3,c):

$$
Y\left(\lambda_{0}\right)=\left(Y_{e x t 0}+Y_{e x t 1}\right) / 2
$$

- for last vertex $\lambda_{m}$ (Fig. 3,d):

$$
Y\left(\lambda_{m}\right)=\left(Y_{\text {extp-1 }}+Y_{\text {extp }}\right) / 2
$$

Imaginary spline vertex formation is related to one of the main B-spline curve characteristics: its beginning is located in triangle $\lambda_{0} \lambda_{1} \lambda_{2}$ (Fig. 4,a), and its end - in triangle $\lambda_{m-2} \lambda_{m-1} \lambda_{m}$ (Fig. 4,b). $B$-spline ambiguity in intervals $\left[\lambda_{0} \ldots \lambda_{1}\right]$ and $\left[\lambda_{m-1} \ldots \lambda_{m}\right]$ leads to mode function deformation (unpredictability) in initial and final intervals. a)

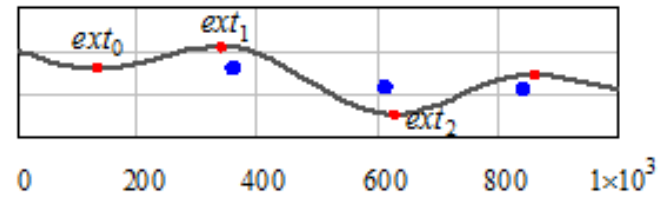

b)

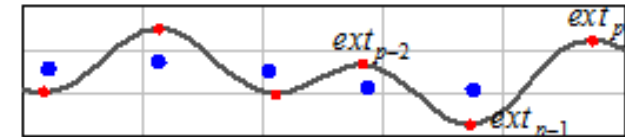

$3 \times 10^{3} \quad 3.2 \times 10^{3} \quad 3.4 \times 10^{3} \quad 3.6 \times 10^{3} \quad 3.8 \times 10^{3} \quad 4 \times 10^{3}$

c)

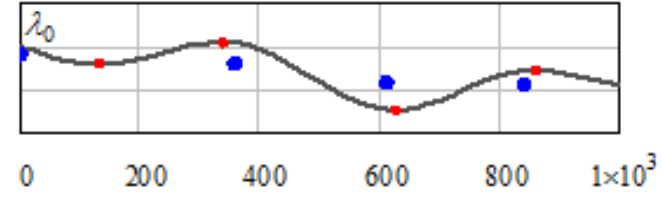

d)

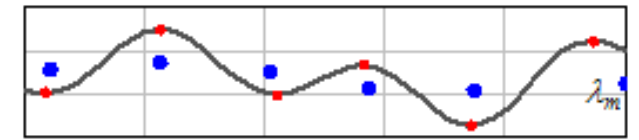

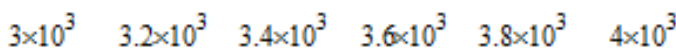

Fig. 3. Illustration of spline vertex definition at the ends of time-series.

a)

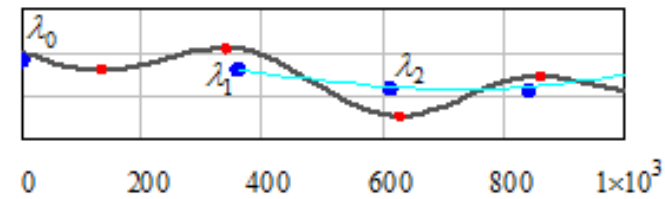

b)

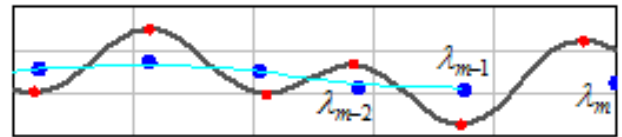

$3 \times 10^{3} \quad 3.2 \times 10^{3} \quad 3.4 \times 10^{3} \quad 3.6 \times 10^{3} \quad 3.8 \times 10^{3} \quad 4 \times 10^{3}$

Fig. 4. Fragments of average $B$-spline in initial (a) and final (b) intervals without additional vertexes.

Elimination of unpredictability of mode function identification is made by calculation of an average $B$-spline considering auxiliary (imaginary) vertexes.

Imaginary vertexes $\lambda_{-1}$ and $\lambda_{m+1}$ in addition to array $\lambda_{0}, \ldots, \lambda_{m}$ are determined by:

$$
\lambda_{-1}=2 \lambda_{0}-\lambda_{1}, \quad \lambda_{m+1}=2 \lambda_{m}-\lambda_{m-1}
$$

As the result, the cubic $B$-spline is built according to the new array: $\lambda_{-1}, \lambda_{0}, \ldots, \lambda_{m}, \lambda_{m+1}$, it begins in vertex $\lambda_{0}$ and ends in vertex $\lambda_{m}$

Operational action - «Determination of an average curve on the base of B-spline basis» is performed for calculation of 
an average curve, which in interval $\left[\lambda_{k}, \lambda_{k+1}\right]$ represents a cubic $B$-spline basis, described by the following equation [7]:

$$
B(t)=\sum_{k=0}^{m-1} \lambda_{k} \cdot N_{k}(t)
$$

where $N_{k}(t)$ - are weighting coefficients of a $k$ cubic $B$-spline basis, determined by:

$$
\begin{aligned}
& N_{0}(t)=(1-t)^{3} / 6, \quad N_{1}(t)=\left(3 t^{3}-6 t^{2}+4\right) / 6 \\
& N_{2}(t)=\left(-3 t^{3}+3 t^{2}+3 t+1\right) / 6, \quad N_{3}(t)=t^{3} / 6
\end{aligned}
$$

The values of an average $B$-spline, calculated according to equation (8), will be found at time intervals not corresponding to registered time intervals of signal being studied, that will not allow one to find the difference between $h_{j}(t)$ and average $B$-spline during the next decomposition procedure. In this regard in this research work, the authors offer to introduce an operational action - "Interpolation of an average B-spline», enabling to determine average $B$-spline values at time intervals of the studied signal.

Piecewise linear interpolation is realized in this operation, allowing one in each interval $\left[\lambda_{k}, \lambda_{k+1}\right]$ to represent the function as:

$$
y(t)=k_{k}\left(t-\lambda_{k}\right)+y_{k}
$$

where $k_{k}=\left(y_{k+1}-y_{k}\right) /\left(\lambda_{k+1}-\lambda_{k}\right)$;

$t$ - registered time intervals of the signal being studied, $\lambda_{k} \leq t \leq \lambda_{k+1}$

$y_{k}-$ an ordinate of the average $B$-spline in point $\lambda_{k}$.

The results of average $B$-spline building $b_{1}(t)(i=0, j=1)$ for the studied signal are shown in Fig. 5.

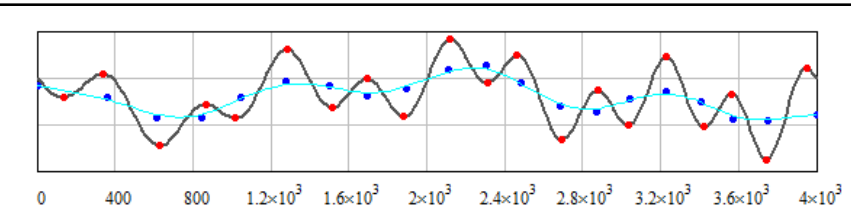

Fig. 5. Illustration of «Average $B$-spline determining» procedure.

\section{Sifting of proto-IMF}

Proto-IMF in terms of the third procedure is determined as difference:

$$
h_{j+1}(t)=h_{j}(t)-b_{j}(t)
$$

where $h_{j+1}(t), h_{j}(t)$ - Proto-IMF (elimination components) in current and previous iterations, accordingly;

$$
b_{j}(t) \text { - an average } B \text {-spline in current } j \text {-iteration. }
$$

\section{Criteria verification of $S$-number}

The verification for stoppage of the iteration process of component elimination $h_{j+1}(t)$ and identification of mode function $c_{i}(t)$ are made with the help of this procedure.

From the possible criteria of stop of the iteration process [8-10], $S$-number criteria is being used in this work. Nnumber $\mathrm{S}$ is determined as iteration index identification, in which proto-IMF $h_{j+1}(t), j=1,2, \ldots, S$ will correspond to empiric mode evaluation

S-number criteria are software-implemented by two operational actions:

1) finding extremum and trivial intersection quantity;

2) checking $I M F$ consistency.

The main point of first action consists in calculation of datum vertexes $\lambda_{k}$ and zero crossing of the average $B$-spline.

The quantity of extremums and zero crossings are compared in terms of the second operation:

$$
N \_\lambda=N \_z e r o \text { or }\left|N \_\lambda-N \_z e r o\right|=1 \text {, }
$$

where $N \_\lambda, N \_z e r o-$ datum vertex and an average quantity of $B$-spline zero crossings accordingly.

If condition (12) is not met, procedures 1-4 will repeat for proto-IMF $h_{j+1}(t)$.

If condition (12) is fulfilled, $S=j$ and proto-IMF (elimination component) $h_{S}(t)$ is taken as a mode function and determined by:

$$
c_{i+1}(t)=h_{S}(t)
$$

where $S$ - empirically determined quantity of iterations for this mode.

\section{Remainder formation}

The software implementation of the fifth procedure provides deletion of the identified (extracted) $I M F$ function from current remainder and forms the new one, having lowfrequency components:

$$
r_{i+1}(t)=r_{i}(t)-c_{i}(t)
$$

where $r_{i}(t)$ - the current remainder;

$$
r_{i+1}(t) \text { - a new remainder. }
$$

\section{Checking remainder monotoneness}

According to [2], the iteration process of mode function identification should be accomplished with maximum remainder «straightening» $r_{N}(t), i=N$, i.e. its transformation into a trend of time-series $f(t)$. Consequently, in terms of the sixth procedure, the outcome analysis of the first procedure implementation «Definition of extrema» is made:

$$
N \_ \text {ext }=0 \text {, }
$$

where $N \_e x t-$ the quantity of localized extremums. 
If condition (15) is not fulfilled, remainder $r_{i+1}(t)$ is being processed as new data according to the above-described algorithm (procedures 1-6).

If condition (15) is met and no extremums has been fixed, the overall remainder will be presented as:

$$
r_{N}(t)=r_{i+1}(t),
$$

and the iteration process of mode function identification is considered as accomplished.

Fig. 6 shows a simulated nonlinear test signal, isolated modal functions and a residue obtained as a result of the $B$ spline of the expansion.

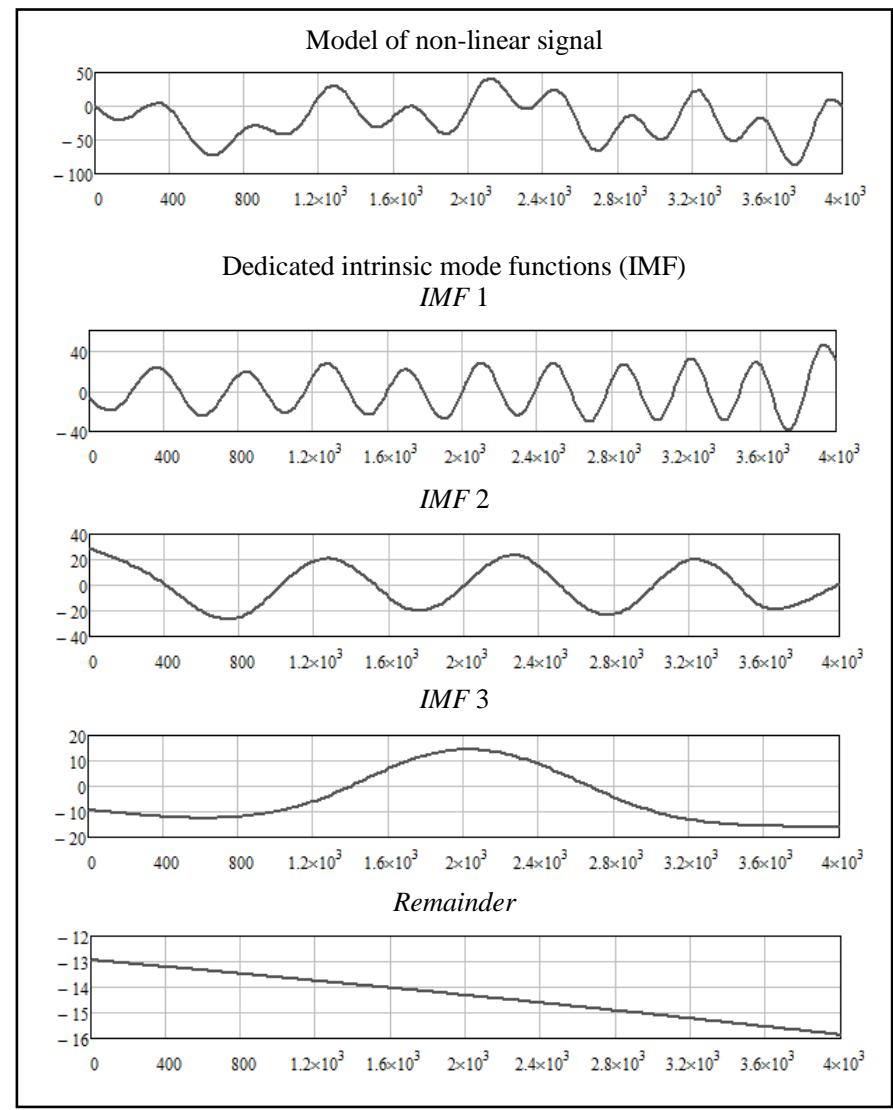

Fig. 6. Comparative results expansions.

Computing time of software implementation for the decomposition algorithm of the studied non-linear electric signal into empiric modes including the mathematical model of evaluation for defining average $B$-spline $b_{m}(t)$, which made up $t=18,1 \mathrm{~s}$ [11]. For comparison, the time of program operation, according to the classical algorithm with the same value, is $t=34,4 \mathrm{~s}$.

\section{CONCLuSions}

1. A $B$-spline decomposition algorithm for non-linear electric signals was offered, differing from classical $E M D$ algorithm by: $b_{j}(t)$

- use of cubic $B$-spline approximation for building average
- decrease of algorithm procedures quantity.

2. An algorithmic model of $B$-spline decomposition was developed. Its core is presented by two internal cycles, inside which there is reference to procedures:

1. Definition of extrema.

2. Average $B$-spline definition.

3. Sifting of proto-IMF.

4. Criteria verification of $S$-number.

5. Remainder forming.

6. Checking of remainder monotoneness.

The software application was registered and developed on the base of the algorithmic model.

3. Mathematical models for each $B$-spline algorithmic model decomposition procedure were developed.

4. Software implementation for $B$-spline non-linear electric signal decomposition increases speed of obtaining results for data record tracing 1,9 time, in contrast to the classical EMD algorithm.

\section{References}

[1] L.A. Semenova, and N.G. Semenova, "Opredelenie ekstremumov nesinusoidalnogo signala," Mezhdunarodnaya konferentsiya "Effektivnaya energetika". Sankt-Peterburg: SPbPU, 2015, pp.87-92.

[2] N.E. Huang, and Samuel S.P. Shen, The Hilbert-Huang transform and its applications. World Scientific Publishing Co. Pte. Ltd., 2005.

[3] A.S. Berdin, L.A. Semenova, Yu.P. Zaharov, and P.Yu. Kovalenko, "Kubicheskaya splajnovaya interpolyaciya i approksimaciya dlya monitoringa perekhodnyh rezhimov v ehnergeticheskih sistemah," Elektroehnergetika glazami molodezhi: nauchnye trudy III Mezhdunarodnoj nauchno-tekhnicheskoj konferencii. Ekaterinburg: UrFU, 2012, Vol. 1., pp. 139-143.

[4] Q. Chen, N.E. Huang, S. Riemenschneider, and Y. Xu, "A B-spline approach for empirical mode decompositions," Advances in Computational Mathematics, vol 24, pp. 171-195, 2006.

[5] P.M. Erohin, L.A. Semenova, Yu.P. Zaharov, and P.Yu. Kovalenko, "Algoritm lokalizacii ehkstremumov v obobshchennom metode ehmpiricheskoj modovoj dekompozicii," Elektroehnergetika glazami molodezhi: nauchnye trudy III Mezhdunarodnoj nauchno-tekhnicheskoj konferencii. Ekaterinburg: UrFU, 2012. Vol. 1, pp. 209-213.

[6] L.A. Semenova, and N.G. Semenova, "Opredelenie srednego B-splayna pri issledovanii nelineynyih protsessov $\mathrm{V}$ elektroenergeticheskih sistemah," Vestnik Cherepovetskogo gosudarstvennogo universiteta, vol 2, pp. 18-22, 2016.

[7] E.V. Shikin, and L.I. Plis, Krivye i poverhnosti na ehkrane komp'yutera. Rukovodstvo po splajnam dlya pol'zovatelej. Moskow: DIALOG-MIFI, 1996.

[8] N.E.Huang, M.C.Wu, S.R. Long, "A confidence limit for empirica mode decomposition and Hilbert spectral analysis," Proc. R. Soc. London, Ser. A, vol. 459, pp. 2317-2345, 2003.

[9] P. Flandrin, G. Rilling, and P. Gonçalvés, "Empirical mode decomposition as a filter bank," IEEE. Signal Processing Letters, vol. 11, No. 2, pp. 112-114, 2004.

[10] N.E.Huang, Z. Shen, S.R. Long, "The empirical mode decomposition and the Hilbert spectrum for nonlinear and non-stationary time series analysis,” Proc. R. Soc. London, Ser. A, vol. 454, pp. 903-995, 1998

[11] L.A. Semenova, and A.A. Parshkov, "Svidetel'stvo o registracii prikladnoj programmy «B-splajn razlozhenie nelinejnyh signalov," UFEHR, № 1216; opublikovano 15.01.16. 
